and so the question naturally arose whether consolidation of the two commissions would not in the end be mutually advantageous to them. Their union was approved by the Executive Committee of the Association at its meeting in April 1939 at Montreux, Switzerland, and so the way was paved for its final consummation at the Washington assembly.

Provision has been made within the new Commission of Snow and Glaciers for a permanent Committee on Glacier Measurements, which will continue the work previously carried on by the Commission of Glaciers, securing systematic records of the annual variations of glaciers. It is Prof. Church's intention to expand the scope of that work, which heretofore was restricted largely to Europe and the United States, so as to take in all of the more important glacier districts of the world, including the Andes of South America, the great mountain chains of Asia, the Alps of New Zealand, and the Arctic regions.

Aside from this enterprise the Commission has planned for the triennium ending in 1942 the following formal programme :

(1) Study of the origin, drift, and dissolution of icebergs, with reference to the forecasting of their seasonal appearance.

(2) Physical changes in the snow-cover conducive to run-off, especially floods.

(3) Study of the crystalline texture of glacier-ice in relation to the mode of movement of glaciers.

In addition, the following four special projects have been assigned to temporary committees :

(a) Standardization of maps of snow-cover and ice-cover for the world.

(b) Uniform classification of different types of snow and snow-cover, and uniform nomenclature for the same.

(c) A system of classification for the international bibliography of snow and ice.

(d) Standardization of methods of snow-surveying and forecasting run-off from snow.

\title{
TRAINING INDUSTRIAL WORKERS
}

$\mathrm{I}^{\mathrm{N}}$ Occupational Psychology (14, No. 1), B. Ungerson discusses the important problem of the training of industrial workers. In spite of the improvement in methods of training learners during recent years, there are still numerous organizations where the only method of training is to let the beginner copy an experienced worker, or he is told what to do and left to get on as best he may.

The resulting efficiency frequently falls short of what he might have attained. It is strange that while it is recognized that games are best learned under the tuition and guidance of an experienced teacher, industrial processes are so frequently allowed to be 'picked up'.

Ungerson divides industrial training into two sections: (1) acquiring knowledge about the job; (2) acquiring facility and speed in making the necessary movements.

The first includes knowledge of technical terms, the tools to use, how to deal with unusual circum- stances; such knowledge can best be taught by a skilled teacher-not necessarily equivalent to the most skilled worker-whose primary business is teaching, not production, and who shall have the requisite qualities for teaching and be given adequate facilities.

In order to teach the correct movements the teacher should himself have a conscious knowledge of them, and for this, motion study is essential. By motion study knowledge is gained of the adequate and useless movements, so that the learner is instructed from the beginning in the right method, and thereby saved from having to unlearn unnecessary movements later.

The principles of motion study which are based on the physiology and psychology of habit formation are no longer a problem for research; it is their application that is needed.

The article is very well balanced and constructively critical, and is of immediate importance.

\section{'SPIKE' DISEASE OF SANDAL}

$\mathrm{F}^{\mathrm{on}}$ R many years after it was first reported in 1898 the so-called 'spike' disease of the sandal tree remained an enigma. Investigations were carried out in a desultory fashion, but no information of value resulted. It is only owing to its alarmingly rapid spread in many parts of the Madras Presidency and elsewhere in Mysore and Coorg that the work of the last few years has resulted in methods of control, the results of careful research work, being successfully elaborated and put into force.

In Indian F'orest Records (New Series. Silviculture, 3 , No. 7 ; 1939) appears a paper entitled "A Note on the Control and Eradication of New Outbreaks of the Spike Disease of Sandal (Santalum album)" by Rao Sahib S. Rangaswami and A. L. Griffith, Sylvi- culturist, Madras. The sandal, as is well known, is a root parasite which lives by haustorizing on the roots of other plants which act as hosts to it. These hosts may be many and varied, for the same sandal tree and the sandal haustoria may wander a considerable distance before a suitable host is found. The sandal tree is not necessarily parasitic on the plants growing nearest to it.

The action of the disease causes both new shoots and leaves to stand up stiff and bristle-like, from which the popular name was derived. The disease itself is a virus disease carried by insects which are probably between $1 / 20$ in. and $\frac{1}{4}$ in. in size. In a diseased area the sources of infection are $(a)$ diseased trees, $(b)$ disease masking trees, and $(c)$ insect vectors. 
Factor $(a)$ is removed by poisoning the diseased trees with 'Atlas Tree Killer' solution and thus killing them at once; factor $(b)$ by tapping all the apparently healthy trees found in the diseased locality, and girdling and treating with poison all those that afterwards show the disease; and factor $(c)$ is eliminated automatically, or the removal of the factors $(a)$ and $(b)$ naturally converts the viruliferous insects into non-viruliferous ones.

As indicating the rapidity of spread of this disease, in the North Salem Forest Division alone 'spike' first appeared in 1913. Twenty years later the infected area was 54,000 acres and in 1938 approximately 99,500 acres. Figures so far available indicate that the annual amounts spent on this research work have been but a fraction of the annual losses inflicted by the disease and of the sums saved. It is a classic example, as the authors say, "that 'academic' research can often be utilized by a practical forest department at a reasonably low additional expenditure to produce 'practical' results of immediate financial value". For quite contrary reasons the attention of the Governments of Burma and Nigeria may be directed to this valuable paper.

\section{LYMPHATIC SYSTEM OF THE ANURA}

A CONSIDERABLE amount of work on the lymphatic system of the lower vertebrates has been published in recent years. A recent treatise (Amer. Anat. Mem., No. 18; 1939) is a survey of that work as it affects the Anura in particular. It is not simply a review of the literature, although this is fully taken into account and critically examined, but is also a description of the development of the lymph-and their relation to the blood-vessels, based upon hundreds of injections (both single and double) of five species of frogs, five species of urodeles, and two species of fish.

Dr. H. M. Knower, the author, first started investigating this problem in 1903, and in 1908 described a microinjector which has proved of considerable value in this rather difficult subject. The work is illustrated by forty excellent drawings on nineteen plates and five text-figures. The drawings are all of preparations of Rana palustris, save five which are of $R$. catesbiana. It is claimed that the method of injection, if carefully checked, provides a more satisfactory approach than the study of transverse sections of uninjected material, and with this most zoologists who have tried tracing these elusive vessels in sections will agree.

The first lymphatics appear when a complete blood circulatory system has been established, and are accessory or supplemental to the veins. They appear in connexion with the pronephric glands and the adjacent segmental glands, and this dorso-lateral plexus, in which the anterior lymph heart develops, drains into the pronephric sinus by a short vein. From this stage the development of the system is followed until the establishment of the definitive condition of the late tadpole. It is a pity that the zoological practice of putting specific names in italics has not been followed and that on p. 23, for example, $R$. nig. appears presumably for $R$. nigromaculata, and that throughout the name toad is used again presumably for some species of Bufo.

\section{SEVENTY YEARS AGO}

NATURE, vol. 2, May I2, I870

\section{A Building for the Learned Societies}

The Statistical Society has done good service to the cause of science in convening representatives of the learned societies, to consider whether it would not be possible to obtain a building for their accommodation worthy of the high position they occupy in this great metropolis. "Some of the societies have no reason to complain, the Royal Society, the Linnean, the Royal Astronomical, the Geological, the Chemical, the Society of Antiquaries, and a few others, are well accommodated, and a solid structure is being raised for them in Piccadilly."

The article goes on to point out that financial objections might be raised to a scheme for a new home for learned societies. To this the reply is that the Government should provide one or more buildings for the purpose. "Nowhere does the State do so little for science as in this country. The estimates for 1870-71 give the entire sum to be applied to the learned societies at $2,370 \mathrm{l}-\mathrm{a}$ sum distributed among very few of them. . . . In addition to this $160,000 l$ are appropriated to a building for certain learned societies in Burlington House; but it will serve for very few of them; and if we are rightly informed, the Government will reoccupy all the buildings in Somerset House now used by learned societies."

In the event that the Government refused to provide funds for a suitable building, the formation is suggested of a joint-stock company, the shares in which would be taken up by the members of the societies interested. "It has been estimated that the probable cost of a building sufficiently commodious, though not ornamental, in some eligible locality near Charing Cross, will be, with the ground-rent, 30,000 $\mathrm{l}$. to $40,000 l$."

\section{Strange Noises heard at Sea off Grey Town}

Mr. Charles Dennehy, of the R.M.S. Shannon, describes a peculiar noise heard on board iron vessels anchored off Grey Town, at the mouth of the River St. Juan, which separates Nicaragua from Costa Rica. Vessels are obliged to anchor in seven to eight fathoms of water outside the bar, and crews are regularly awakened at night by "a peculiar metallic vibratory sound". This noise, which commences "with a marvellous punctuality at about midnight", continues for about two hours with one or two very short intervals. The noise is not heard on shore, or on coppered wooden vessels. The bottom consists of a heavy dark sand and mud containing much vegetable matter brought down by the river. "The ship is undoubtedly one of the principal instruments in its production. She is in fact for the time being converted into a great musical sounding board."

The letter is followed by the brief comment : "Our correspondent should dredge.-Ed."

ReFERENCE is made to the fact that a considerable number of papers are on hand at the Royal Society, and only two more meetings have been arranged for the session. Were not the present arrangements of the Royal Society meetings made to meet conditions long since passed away? And since the flow of papers into the Society has largely increased, why should not the outflow be a little accelerated? 